\title{
Epithelial-to-mesenchymal transition status of primary breast carcinomas and its correlation with metastatic behavior
}

\author{
C. D. Savci-Heijink ${ }^{1}$ (D) H. Halfwerk ${ }^{1}$ - G. K. J. Hooijer ${ }^{1}$ J. Koster $^{2} \cdot$ H. M. Horlings ${ }^{3} \cdot$ S. L. Meijer ${ }^{1}$ - M. J. van de Vijver ${ }^{1}$
}

Received: 14 September 2018 / Accepted: 6 December 2018 / Published online: 4 January 2019

(c) The Author(s) 2019

\begin{abstract}
Background Epithelial-to-mesenchymal transition (EMT) has been implicated as an important step in the development of distant metastases. We therefore wished to study EMT status of primary breast carcinomas from patients who during followup developed distant metastases.

Methods mRNA expression profiles of primary breast carcinoma samples $(n=151)$ from patients who developed metastatic disease were analyzed and EMT status was designated using a previously described EMT-core signature. EMT status of the primary tumor was correlated to clinicopathological characteristics, molecular subtypes, metastasis pattern, chemotherapy response and survival outcomes. In addition, using immunohistochemistry, the expression levels of several proteins implicated in EMT were studied (CDH1, CDH2, NAT1, SNAI2, TWIST1, VIM, and ZEB1) compared with the designated EMT status and survival.

Results Utilizing the 130-gene-EMT-core signature, $66.2 \%$ of the primary tumors in the current study was assessed as EMTactivated. In contrast to our expectations, analyses revealed that $84.6 \%$ of Luminal A tumors, $65.1 \%$ of Luminal B tumors, and $55.6 \%$ of HER2-like had an activated EMT status, compared to only $25 \%$ of the basal-type tumors $(p<0.001)$. EMT status was not correlated to the pattern of metastatic disease, metastasis-specific survival, and overall survival. Similarly, there was not a significant association between EMT status of the primary tumor and chemotherapy response in the metastatic setting. Immunostaining for NATI and TWIST1 correlated with the EMT status ( $p 0.003$ and $p 0.047$, respectively). Multivariate analyses showed that NAT1 and TWIST1 staining was significantly associated with EMT status regardless of the estrogen receptor status of the tumors ( $p$ values: 0.020 and 0.027 , respectively).

Conclusions The EMT status of breast cancers, as defined by the presence of a core EMT gene expression signature is associated with non-basal-type tumors, but not with the pattern of distant metastasis. Of several potential immunohistochemical EMT markers, only NATI and TWISTI expression levels were associated with the gene expression-based EMT status.
\end{abstract}

Keywords Breast carcinoma $\cdot$ Chemoresistance $\cdot$ Chemotherapy response

Electronic supplementary material The online version of this article (https://doi.org/10.1007/s10549-018-05089-5) contains supplementary material, which is available to authorized users.

C. D. Savci-Heijink

c.d.savciheijink@amc.uva.nl

M. J. van de Vijver

m.j.vandevijver@amc.uva.nl

H. Halfwerk

j.b.halfwerk@amc.uva.nl

G. K. J. Hooijer

g.k.hooijer@amc.uva.nl

J. Koster

jankoster@amc.uva.nl

H. M. Horlings

h.horlings@nki.nl

\section{S. L. Meijer}

s.1.meijer@amc.uva.nl

1 Department of Pathology, Amsterdam UMC, University of Amsterdam, Meibergdreef 9, 1105 AZ Amsterdam, The Netherlands

2 Department of Oncogenomics, Amsterdam UMC, University of Amsterdam, Meibergdreef 9, 1105 AZ Amsterdam, The Netherlands

3 Department of Pathology, The Netherlands Cancer Institute, 1066 CX Amsterdam, The Netherlands 


\section{Abbreviations}

EMT Epithelial-to-mesenchymal transition

CT Chemotherapy

ER Estrogen receptor

HER2 Human epidermal growth factor receptor 2

\section{Introduction}

Epithelial-to-mesenchymal transition (EMT) is a complex and dynamic process that involves transdifferentiation of the cells by means of changes in the cell state. This process of epithelial-mesenchymal plasticity plays an established role in embryogenesis and early organ development [23, 30, 48]. EMT is initiated with the activation of transcription factors such as Snail, Twist, Slug, and Zebl and is regulated by the modulation of multiple epigenetic regulatory mechanisms $[43,48]$. This process results in the loss of epithelial features and acquiring mesenchymal properties such as motility, invasiveness, and resistance to apoptosis, eventually leading to colonization and metastasis formation [40]. It is thought that once colonization of the tumor cells at distant sites has occurred, these EMT-derived mesenchymal cells with stem cell-like properties go through mesenchymal-to-epithelial transition (MET) and re-gain epithelial features and continue to proliferate [3]. Along with its role in cancer metastasis, epithelial-mesenchymal plasticity is also indicated as the origin of systemic therapy resistance in breast cancer stem cells $[20,25,56]$.

Several transgenic mouse models have provided evidence for the existence of tumor cells with a mesenchymal phenotype in different types of carcinomas [18, 27, 34, 41]. Using genetically engineered knock-in reporter mouse lines and fluorescence activated cell sorting, Ye et al. have isolated Slug $^{+}$and Snail ${ }^{+}$cells in normal mammary tissue. They have shown that epithelial-to-mesenchymal transition-inducing transcription factors (EMT-TFs) Snail, Twist, and Zebl were expressed in stromal fibroblasts surrounding the mammary ducts, whereas Slug was found to be expressed in basal mammary epithelial cells. Adopting a transgenic model of mammary tumor development, as tumors progressed to more undifferentiated phase(s), they have identified that the Snail ${ }^{+}$ cancer cells dissociating from epithelium acquired an elongated morphology similar to mesenchymal cells. These cells were found to have lost E-cadherin expression and activated expression of Zeb1. During the process of tumor progression, these cells were also shown to gain CK14 expression especially at the invasive edges of the organoids. With these results, the authors have demonstrated the potential role of Snail and subsequent EMT activation in obtaining basal features usually seen in more aggressive breast tumor types [59].
Despite the increasing interest in this dynamic process, it is still unknown what the exact role of EMT is in the development of distant metastases in human breast cancer. Several authors have suggested that the EMT state of a tumor can range from partial to full as opposed to a static event leading to gain or loss of a function [7, 19, 21, 43]. These studies have also identified that the main tumor bulk and the invasive front of the tumor differ: the invasive front being the main area for the EMT program to interact closely with the tumor microenvironment. Individual tumor cells which undergo EMT have been defined at the invasive front of the tumor and have been described as individual cells or small cell groups detaching from the main mass into the adjacent stroma [4, 19, 33, 54, 55]. The difficulty to recognize and distinguish these individual cells from the pre-existing stromal cells has contributed to the controversy of existence of clinical evidence of EMT.

Recently, a quantitative EMT scoring system based on gene expression profiling of cell lines was identified. It was shown that each cancer type had its own characteristic EMT spectrum; however, EMT status of the tumors did not correlate with poorer survival or to chemotherapy resistance [44]. A prior EMT-core signature generated by using EMTinduced human mammary epithelial cells was found to be strongly correlated to metaplastic and claudin low breast cancer, but not to other gene expression-based subtypes; and lacked to show correlation with poorer survival outcome [46].

To explore the accordance of the concept to reconcile the EMT-ness in clinical practice, we have conducted a study utilizing gene expression profiling data from primary breast cancers from a group of patients with known metastatic disease. In the current study, the association between EMT status of the primary tumors and their pattern of metastatic disease and the possibility of determining this EMT status with the help of selected routine immunohistochemical stains was investigated.

\section{Materials and methods}

\section{Patient and tumor samples}

This study was conducted in line with national ethical guidelines of 'Code for Proper Secondary Use of Human Tissue' developed by the Federation of Medical Societies (FMWV) in the Netherlands [53]. Metastatic breast cancer patients from the Academic Medical Center and the Netherlands Cancer Institute with available frozen material from their primary tumors were identified. Relevant detailed clinical information on metastatic disease including the metastasis site, timeline of the metastatic disease, and the outcome measures (metastasis-specific survival and 
overall survival) was collected from a group of 151 patients. The clinicopathological features of these tumors and their affiliated metastasis pattern have been reported previously [37]. For each patient, administered chemotherapy and therapy-related data including chemotherapy response for the given regimen(s) during the metastatic process were carefully recorded as previously described in a subgroup of the patients $(n=142)$ [38].

The histologic sections from the primary tumors were reviewed and additional routine staining techniques were applied to determine the hormone receptor status of the tumors [37].

\section{Identification and validation of EMT status}

Comparing the first and the last H-E-stained sections, the samples with more than $50 \%$ tumor cells were used for the gene expression profiling experiments. The details about the RNA isolation and gene expression microarrays HumanHT-12 v4 Expression BeadChip arrays [Illumina, Inc., $>47,000$ probes] have been reported previously [39]. Full information on RNA amplification, labeling, and hybridization can be also found on the Illumina website (http//www.illumina.com). Following the robust spline normalization, the data were $\log 2$ transformed and processed by ComBat (https://www.bu.edu/jlab/wp-assets/ComBat/Downl oad_files/ComBat.R) to tailor the batch effects.

The generated data were analyzed with help of R2 (Microarray Analysis and Visualization Platform, http// r2.amc.nl). Molecular subtypes were assessed for each tumor using the Pam50 classifier [32]. Also the percentage of tumor cells on the slides used for gene expression profiling experiments were correlated to the molecular subtypes.

To designate the EMT status of each tumor, the EMT-core gene list of Groger et al. was utilized [15]. The 130 genes of this EMT-core gene list were first mapped to the Illumina platform via Gene Symbol ID. In case of existence of multiple probes for one gene, the one with highest average signal across the samples was selected. Subsequently, a K-means clustering method was applied to separate the tumors into two groups as EMT-activated or not-EMT-activated. By means of K-means clustering method, the EMT-core gene list was also applied to an independent set composed of a subset of a combined database including 376 breast cancer samples with distant organ metastases [17]. Additionally, based on gene expression levels, $z$ scores were calculated for each tumor to define the EMT status in accordance with distribution of the $z$ scores. EMT status identified by K-means method and z-scores of the tumors were subsequently compared to verify the identified EMT status of the given tumor. Given the significant concordance in assigned EMT status with K-means method and the $z$ scores method ( $p$ 3.92e-20) in our dataset, further analyses and comparisons were carried out on the EMT status based on K-means method.

To further reconcile the EMT-ness with the help of immunohistochemical stains, a subset of 46 tumors (EMTactivated, $n=23$ and not-EMT-activated, $n=23$ ) were selected. The heat map created by supervised clustering with the EMT-core signature was carefully observed. Based on the current literature information on their established role in EMT, a subgroup of 7 proteins $(\mathrm{CDH1}, \mathrm{CDH} 2, \mathrm{NAT1}$, SNAI2, TWIST1, VIM, and ZEB1) was selected for further evaluation. To test the representativeness of this subset of genes, respectively, a K-means clustering method and a $t$ test were carried out first to classify the tumors into two groups according to their EMT status and then to validate the performance of this classification in the same study set (used for immunophenotypic evaluation).

\section{Immunophenotypic evaluation}

Whole-mount slides of the tumors from a subgroup of patients (total $n=46$; EMT-activated $n=23$, not-EMT-activated $n=23$ ) were selected for the additional immunophenotypic evaluations.

Immunohistochemical staining for E-Cadherin ( $\mathrm{CDH} 1$, clone 24E10, Cell signaling), $\mathrm{N}$-cadherin ( $\mathrm{CDH} 2$, clone $32 \mathrm{~N} /$ Cadherin, BD transduction Laboratories), NAT1 (Abcam), SNAI2 (Abcam), Vimentin (clone D21H3, Cell Signaling), and ZEB1 (Sigma Life science) was performed using an automated slide preparation system (Benchmark XT, Ventana Medical Systems, Tucson Arizona, USA). The signal detection for immunohistochemistry was performed with a biotin-free ultraview universal DAB detection Kit (Ventana medical systems). Immunohistochemical staining for TWIST1 (Clone Twist2C1a, Abcam) was performed manually with a Bright DAB detection.

The immunostained slides were scored by two pathologists (C.D. S-H, S.L.M). The invasive edges and the main tumor mass were evaluated separately. Immunostaining patterns for the other antibodies were evaluated semi-quantitatively; the extent and the intensity of the expression were scored for each antibody. For NAT1, SNAI2, TWIST, and $Z E B 1$, a cut-off value of $10 \%$ was used to designate tumors as positive or negative. Absence of E-Cadherin expression in $>1 \%$ of the tumor cells was considered as loss of expression and presence of $\mathrm{N}$-cadherin and Vimentin expression in $>1 \%$ of tumor cells was noted as gain of expression. Immunohistochemical findings were then correlated to the designated EMT status.

\section{Statistical analysis}

The association between the EMT status of the tumors and clinical variables was further investigated with multivariate 
logistic regression tests applying SPSS Statistics for Windows (Release version 21.0; IBM Corp. 2012, Armond, NY). Univariate and additional multivariate regression tests [adjusted for ER (positive versus negative)] were utilized for the comparisons of the immunostaining results to the EMT status. Hazard ratios (HRs) were presented with their 95\% confidence intervals (CIs). The statistical tests were two-sided and $p$ value being less than 0.05 was considered to be significant.

\section{Results}

We studied epithelial-mesenchymal transition status, as assessed by gene expression profiling, for 151 primary invasive breast carcinomas of patients whom all developed metastatic disease. Clinical and pathologic characteristics of the primary breast tumors have been previously described [37] and are shown in Table 1.

Table 1 Clinical and pathological characteristics of metastatic breast cancer patients

\begin{tabular}{|c|c|c|}
\hline & $N$ & $\%$ \\
\hline \multicolumn{3}{|l|}{ Age at diagnosis, years } \\
\hline$<50$ & 83 & 52.9 \\
\hline$>50$ & 74 & 47.1 \\
\hline \multicolumn{3}{|l|}{ Surgical procedure } \\
\hline None & 4 & 2.8 \\
\hline Mastectomy & 73 & 51.8 \\
\hline Breast conserving & 64 & 45.4 \\
\hline \multicolumn{3}{|l|}{ Adjuvant therapy } \\
\hline None & 30 & 21.1 \\
\hline Only CT & 50 & 35.2 \\
\hline Only HT & 17 & 12.0 \\
\hline $\mathrm{CT}+\mathrm{HT}$ & 45 & 31.7 \\
\hline \multicolumn{3}{|l|}{ Lymph node status } \\
\hline None & 43 & 29.3 \\
\hline $1-3$ positive & 48 & 32.7 \\
\hline$>3$ positive & 56 & 38.1 \\
\hline \multicolumn{3}{|l|}{ Histology } \\
\hline Ductal & 134 & 86.5 \\
\hline Lobular & 14 & 9.0 \\
\hline Other & 7 & 4.5 \\
\hline \multicolumn{3}{|l|}{ Tumor grade } \\
\hline 1 & 13 & 8.6 \\
\hline 2 & 84 & 55.3 \\
\hline 3 & 55 & 36.2 \\
\hline \multicolumn{3}{|l|}{ Time to distant metastasis ${ }^{\mathrm{a}}$} \\
\hline Early & 117 & 77.0 \\
\hline Late & 35 & 23.0 \\
\hline Metastasis at first presentation & & \\
\hline
\end{tabular}

\begin{tabular}{lrl}
\hline & $N$ & $\%$ \\
\hline No & 141 & 92.8 \\
Yes & 11 & 7.2 \\
Multiple metastasis sites at first presentation & & \\
No & 97 & 64.2 \\
Yes & 54 & 35.8 \\
Multiple metastasis sites during follow-up & & \\
No & 37 & 24.5 \\
Yes & 114 & 75.5 \\
\hline
\end{tabular}

$C T$ chemotherapy, $H T$ hormonal therapy

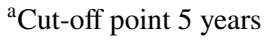

Using the 130-gene-EMT-core signature, $66.2 \%(n=100)$ of the primary tumors in the current study was assigned as EMT-activated and $33.8 \%(n=51)$ as not-EMT-activated. The heat map shown in Fig. 1 displays the gene expression profiling pattern of 130 genes of the EMT-core signature. In the independent dataset, $72.9 \%(n=274)$ of the tumors was identified as EMT-activated and $27.1 \%(n=102)$ as not-EMT-activated.

Comparisons of the histopathological characteristics of the tumors from EMT-activated group with the tumors from not-EMT-activated group showed that $76.9 \%$ of Grade 1 and $78.5 \%$ of grade 2 tumors had an activated EMT status as opposed to the $45.5 \%$ of grade 3 tumors $(p<0.001)$. Histologic type or the size of the tumor was not found to be correlated with the gene expression-based EMT status ( $p$ 0.635).

Among ER-positive and PR-positive tumors $77.8 \%$ and $81.1 \%$ were identified as EMT-activated, respectively ( $p$ $<0.001$ ). Of Luminal A tumors $84.6 \%$, of Luminal B tumors $65.1 \%$, and of HER2-like $55.6 \%$ was assessed as having an activated EMT status, whereas only $25 \%$ of the basaltype tumors were assigned to the EMT-activated group ( $p$ $<0.001)$. Similarly, in the independent dataset [17] of total 376 tumors, $100 \%$ of the Luminal A tumors, $97.5 \%$ of the Luminal B tumors, 92,1\% of HER2-like tumors, and 8,3\% of the basal-type tumors were designated as EMT-active ( $p$ $<0.001)$. Mean tumor percentage in the basal-type tumors was $72.1 \%$ (range 66.8-77.3). In the non-basal tumor groups, mean percentage was $58.9 \%$ in luminal A type, $65.8 \%$ in luminal B type, and $62.1 \%$ in HER2-like tumors $(p<0.001)$.

EMT status did not differ between the patients who developed metastasis within 5 years' time and the ones who developed metastatic disease later than 5 years $(p 0.310)$. Regarding the metastasis site, out of 108 patients who developed bone metastasis $72.2 \%$ had an EMT-activated primary tumor ( $p 0.021$ ) versus $65.2 \%$ of the tumors of the patients with visceral metastasis ( $p$ 0.698).

Median overall survival time was 60 months and 37 months for the EMT-activated and the not-EMT-activated group, respectively ( $p$ 0.162). Metastasis-specific survival time was 33 months for the patients with EMT-activated 
EMT-activated

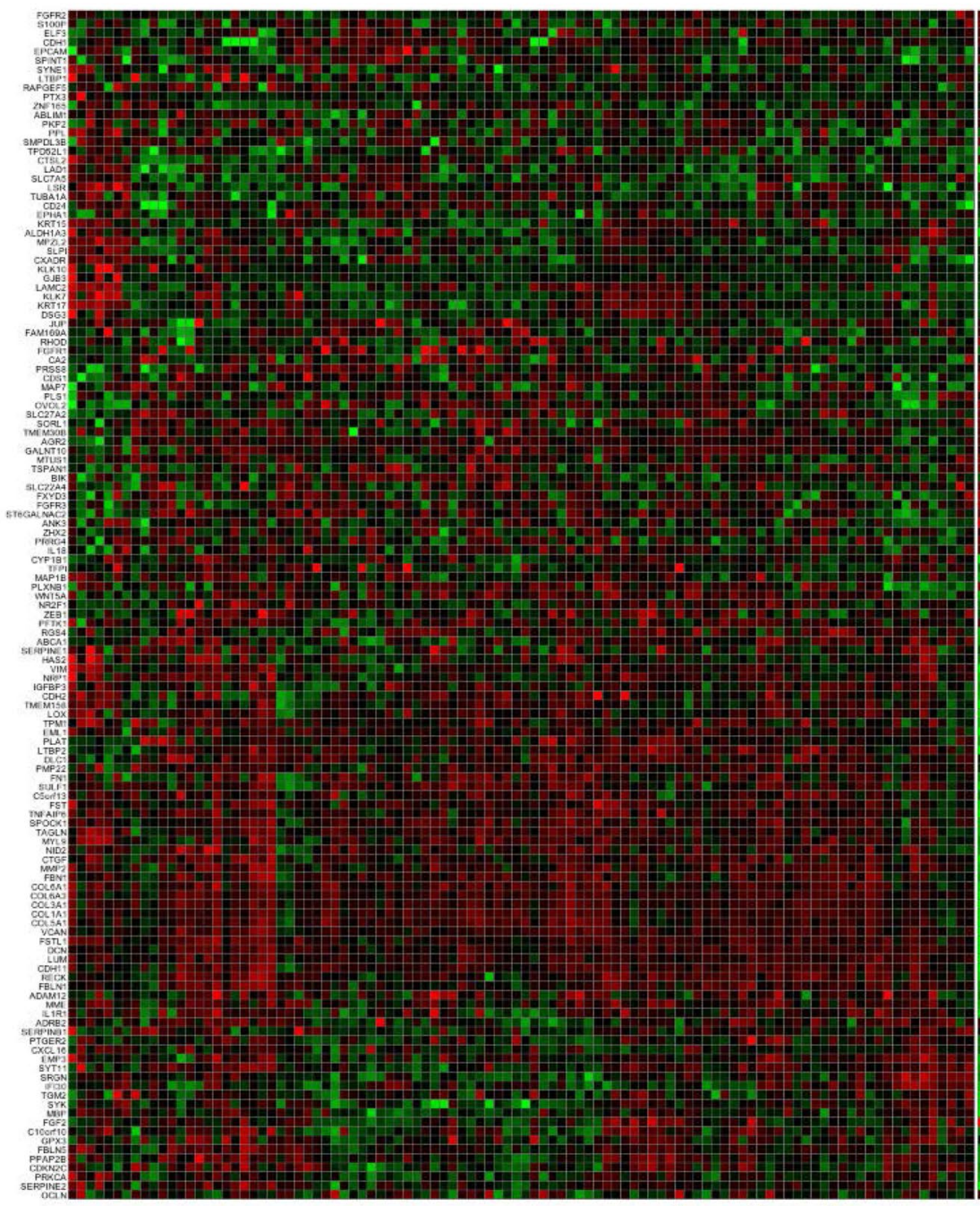

not-EMT-activated

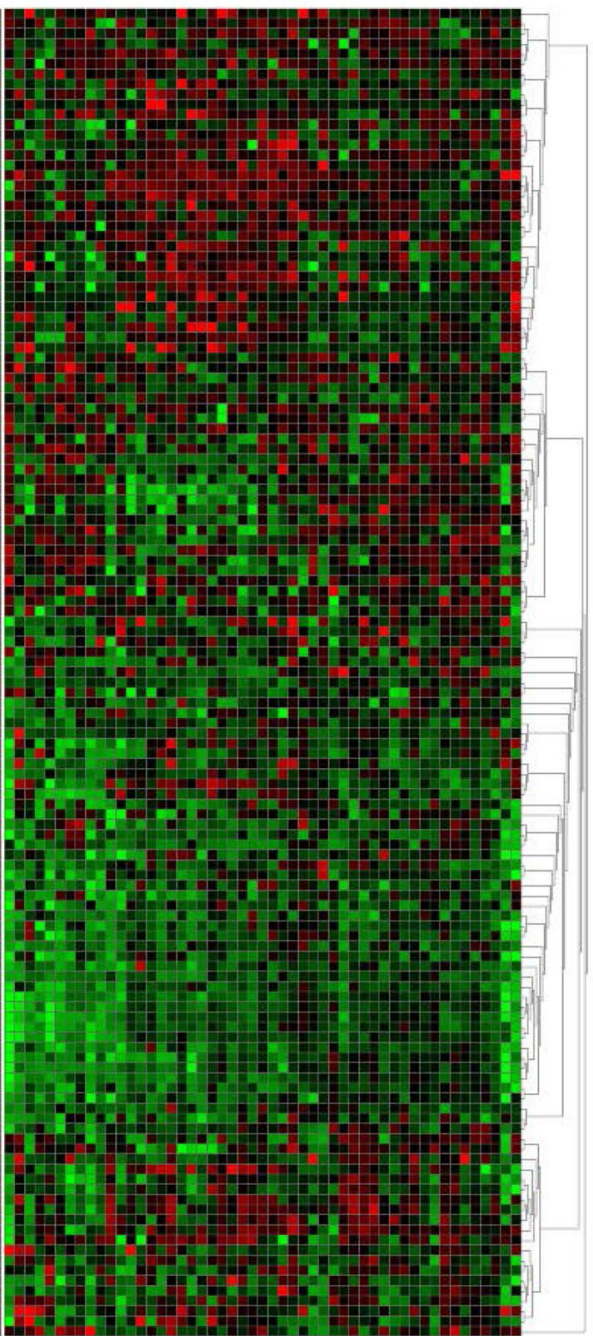

Fig. 1 Heat map shows the gene expression profiling pattern of 130-genes of EMT-core signature among 151 patients. For each primary tumor, the expression level of the specific gene is exhibited as red, if up-regulated and green, if down-regulated

tumors and 19 months for those with non-EMT-activated tumors ( $p$ 0.036) (Fig. 2).

118 patients underwent chemotherapy treatment; $48.1 \%$ of the patients with EMT-activated tumors showed a response versus $31.4 \%$ of those with not-EMT-activated ones $(p 0.130)$.

We subsequently wished to study the correlation of the gene expression-based EMT status of the tumors with the expression of EMT-associated proteins in using immunohistochemistry in a subset of 46 tumors (23 EMT-activated; 23 not-EMT-activated); the findings are summarized in Table 2.

Immunohistochemical evaluation for all stains revealed comparable expression patterns at the invasive edges and at the center of the tumors; therefore, analyses were further carried out based on a single score.
The expression patterns of staining for E-cadherin, $N$-cadherin, Vimentin, SNAI2, and ZEB1 did not differ between the EMT-activated and not-EMT-activated groups ( $p$ values: $1.000,0.699,0.109,1.000$, and 0.071 , respectively).

NAT1 expression was scored as positive in 25 cases with a range of $30-100 \%$ positivity in the tumor cells. Out of positively stained cases, $72 \%$ was assigned to the EMT-activated group; of negatively stained cases $76.2 \%$ was marked as not-EMT-activated ( $p$ 0.003). Further evaluations showed that NAT1 expression was not significantly correlated to the overall survival ( $p$ 0.223) and metastasis-specific survival ( $p$ 0.146).

TWIST1 expression was found to be positive in 13 cases with $76.9 \%$ of these tumors being EMT-activated and of 

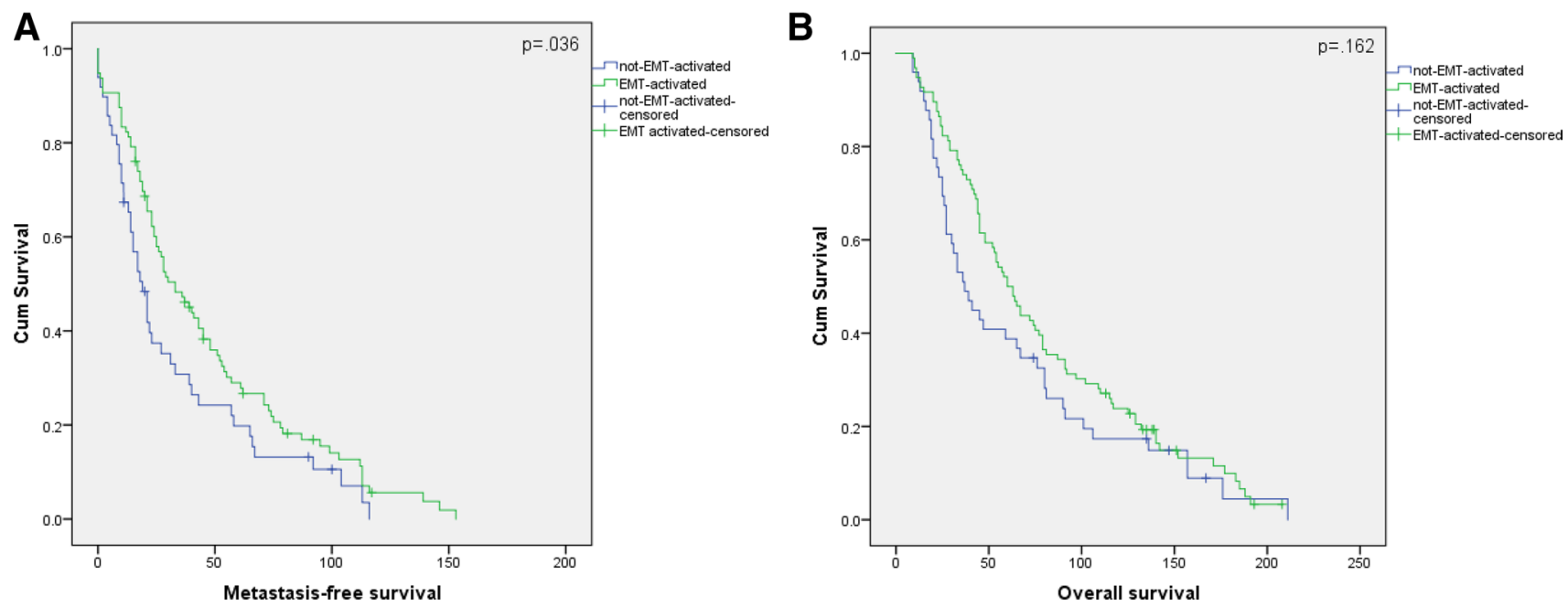

Fig. 2 Metastasis-specific (A) and overall (B) survival curves of breast cancer patients according to EMT status. Kaplan-Meier plots of patients show that EMT-activated tumors had better survival outcomes compared to the tumors with not-EMT-activated status

Table 2 Correlation of immunohistochemical findings and EMT status

\begin{tabular}{llrrr}
\hline & IHC & EMT status & & \\
\cline { 3 - 5 } & & Non-activated & Activated & $p$ \\
\hline CDH1 & Negative & 3 & 2 & 1.000 \\
& Positive & 20 & 21 & \\
CDH2 & Negative & 20 & 18 & 0.699 \\
& Positive & 3 & 5 & \\
NAT1 & Negative & 16 & 5 & 0.003 \\
& Positive & 7 & 18 & \\
SNAI2 & Negative & 7 & 6 & 1.000 \\
& Positive & 16 & 17 & \\
TWIST1 & Negative & 20 & 13 & 0.047 \\
& Positive & 3 & 10 & \\
VIM & Negative & 19 & 23 & 0.109 \\
& Positive & 4 & 0 & \\
ZEB1 & Negative & 17 & 10 & 0.071 \\
& Positive & 6 & 13 & \\
\hline
\end{tabular}

IHC immunohistochemistry, EMT epithelial-to-mesenchymal transition

$60.6 \%$ of TWIST1 negative tumors belonged to the notEMT-activated group ( $p$ 0.047). TWIST1 expression was not found to be significantly correlated with overall survival and metastatic-specific survival ( $p 0.675, p 0.461$, respectively). Figure 3A, B illustrates expression of NAT1 and TWIST1 in an EMT-activated and a not-EMT-activated tumor.

To investigate the additional role of NATI and TWISTI staining to predict EMT status, multivariate regression analyses were applied. Multivariate analyses results are displayed in Table 3 and shows that positive NATI and TWISTI staining was significantly correlated to EMT-activated status independent of ER status of the tumor ( $p$ values: 0.020 and 0.027 , respectively).

\section{Discussion}

In this study, gene expression profiles from primary breast carcinomas of patients with known metastatic disease have been utilized to assess the EMT status of the primary tumor. Subsequently, the designated EMT status has been correlated to the metastatic behavior and survival outcomes. In addition, the expression of EMT-associated proteins to the EMT status as assessed by gene expression profiling was studied.

The previously suggested reciprocal link between basaltype breast cancer as assessed by immunohistochemistry and EMT [35] was not found in our dataset. Unexpectedly, the low-grade tumors tended to be more frequently EMTactivated than high-grade tumors.

The role of epithelial-to-mesenchymal transition (EMT) in cancer progression has been demonstrated in several tumor models. Yet, the translation of this concept to clinical breast cancer remains problematic and it has been argued that EMT may not be required for the development of distant metastases [45]. Recent investigations focusing on these debates have led to adoption of a new concept of EMT indicating the flexibility and intermediate hybrid state of this process rather than a rigid state $[1,19,21,43,60]$. These recently proposed transitional states and the heterogeneity of EMT may explain the difficulty to visualize the EMT status. In our study, we were not able to show any significant association between EMT status and the metastasis time (early 


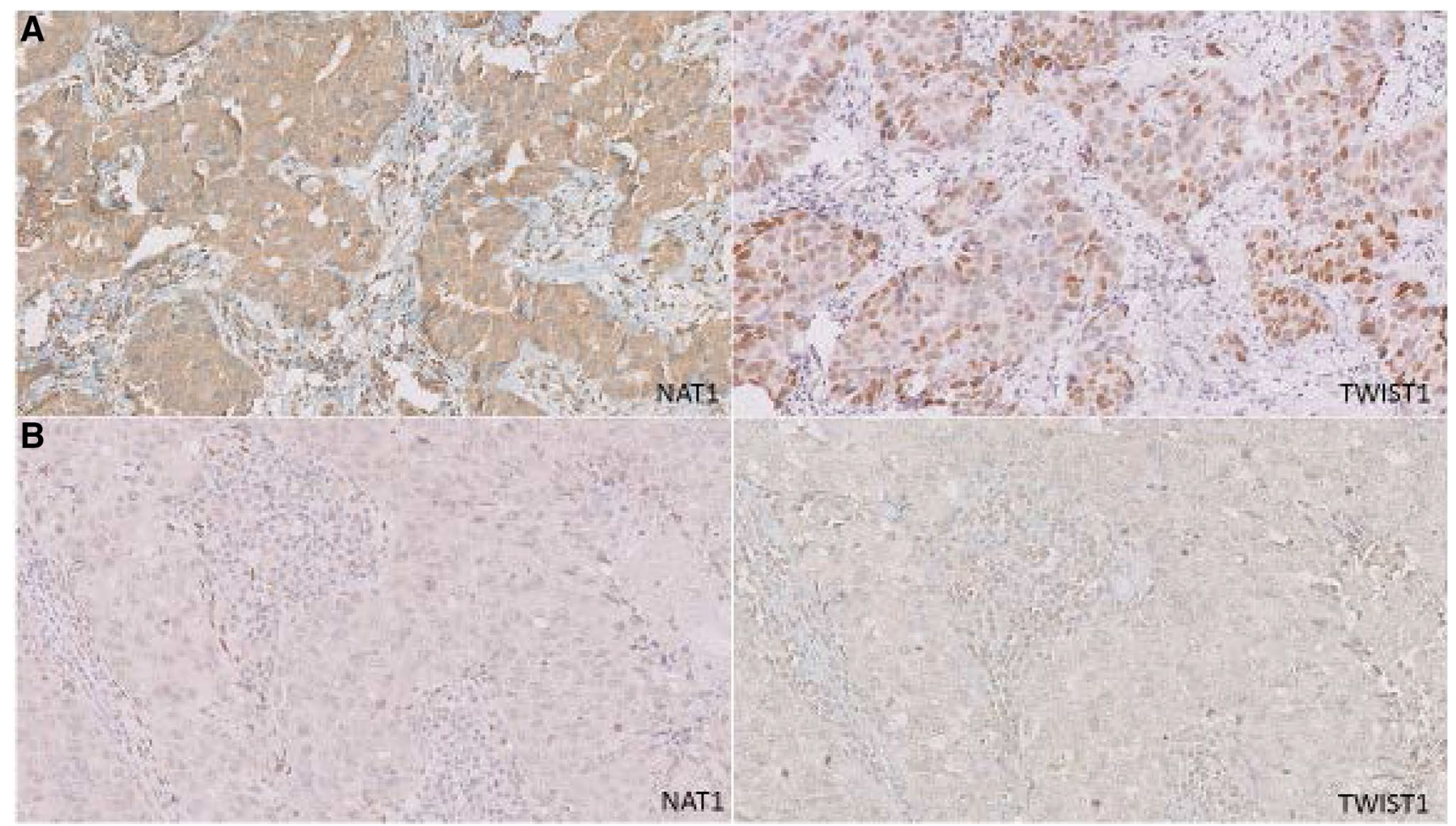

Fig. 3 Microscopic images displaying immunoexpression for NAT1 and TWIST1 for an EMT-activated (A) and a not-EMT-activated (B) tumor

Table 3 Multivariate analyses results displaying the correlation between immunohistochemical findings and EMT status

\begin{tabular}{lrllll}
\hline & \multicolumn{1}{l}{ B } & Wald $x^{2}$ & $p$ & Odds ratio & $95 \%$ CI \\
\hline ER status & -1.11 & 0.68 & 0.410 & 0.33 & $0.02-4.63$ \\
NAT1 status & 3.18 & 5.37 & 0.020 & 23.98 & $1.63-352.24$ \\
TWIST1 status & 2.12 & 4.92 & 0.027 & 8.35 & $1.28-54.55$ \\
\hline
\end{tabular}

$E M T$ epithelial-to-mesenchymal transition, ER estrogen receptor

versus late metastasis). Overall survival and metastasis-specific survival outcomes did not differ significantly between EMT-activated and not-EMT-activated group, either. Although these results seem to be opposing to common concept that EMT-active status has bad prognostic implications, they can be due to proposed intermediate hybrid states. Tan et al. have already addressed this issue with their study including several types of cancer tissue [44]. Applying a generic EMT signature, they have quantitatively estimated the extent of EMT in human tumor samples and cell lines. In this study, authors have not found a relation between EMT status and overall and disease-free survival. Particularly in the breast carcinoma samples, they have shown that tumors with mesenchymal (Mes) profile appeared to have better prognosis than the ones with epithelial (Epi) profile. The authors have suggested the role of stromal component and the distribution of molecular subtypes for the contradictory results. Concordantly, in this study, we have demonstrated that the percentage of tumor cells, hence the epithelial component differed among the molecular subtypes and luminal type tumors, had relatively more stromal component than the basal-type tumors, which may explain the association between luminal type tumors and the EMT-core signature $(p<0.001)$.

Next to its association with cancer progression and metastasis formation, EMT has been linked to chemoresistance in several cancer types $[8,12,20,40,56,62,64]$. Several studies have demonstrated that cells with an EMT profile, rather than directly establishing metastasis, showed more resistance to chemotherapy (CT) and have indicated the potential role of EMT-targeted therapy. In our current study, we were not able to demonstrate a link between EMT status of the primary breast tumors and response to $\mathrm{CT}$ in the metastatic setting. The study conducted by the group of Tan has also failed to show a direct translation of EMT status to chemotherapy resistance [44]. These authors have concluded that in addition to acquiring EMT, gaining stem cell-like properties plays an important role in chemoresistance. Several studies have already shown that overexpression of EMT-inducing transcription factors leads to changing luminal lineage cells to a more stem cell-like trait suggesting that these breast cancer stem cells showing an EMT-like profile are more chemotherapy resistant $[8,12,16,40]$. A generic EMT signature which is developed to assess the EMT status, may not be the 
optimal tool to assess the stemness of the cancer cells and their potential response profile [3, 13, 35, 44].

Activation of an EMT program has been suggested as a critical event for cancer progression which grants epithelial cancer cells with more invasive mesenchymal phenotypes [48]. Direct visualization of these cells going through this process and their morphological changes remains an area of interest. To recognize the cancer cells with EMT phenotype, we have performed immunostaining for $C D H 1$, CDH2, NAT1, SNAI2, TWIST1, VIM, and ZEB1. We were not able demonstrate the significant difference between EMT-activated and not-EMT-activated group regarding $C D H 1, C D H 2$, SNAI2, VIM, and ZEB1 expression, in the tumor bulk as well as at the invasive edges of the tumor tissue. Noteworthy, the staining pattern of TWIST1 and NAT1 have appeared to be related to the EMT status of the primary tumor. We have already pointed out the link between NAT1 and EMT status in a previous gene expression profiling-based study [39] and its potential role, particularly as a drug target in cancer development $[11,42$, 49]. N-acetyltransferase 1 (NAT1) is a human enzyme that metabolizes arylamine and hydrazine-class drugs [5]. Next to its association with survival of breast epithelial cells [2], NATl has been proposed as a useful biomarker for breast cancer $[11,22,50,51]$. Several studies have shown that knockout of NATl led to the modification of intracellular actin which resulted in suppression of invasion and metastasis. Loss of NAT1 has also been reported to reduce the cell-to-cell contact growth and enhance the up-regulation of E-cadherin [50, 51]. TWIST1, a helix-loop-helix domain containing transcription factor, carries a key regulator role in organogenesis and its hypermethylation and overexpression have been identified in several tumor types $[10,14,26,28$, $31,57,63]$. This transcription factor has been implicated in many steps of cancer progression (invasion, metastasis, angiogenesis, cancer stemness) $[6,9,52,58]$. The association between TWIST1 and EMT, which was first proposed by Yang et al. [57], has been confirmed in different types of cancer [24, 29, 36, 47, 61].

Many investigators have faced difficulties to detect cancer cells with EMT phenotype. To overcome the main obstacle which is to differentiate the stromal fibroblasts from the cells with EMT phenotype, Yu et al. conducted a study using RNA in situ hybridizations on HER2-positive breast tumors in order to distinguish primary tumor cells from the surrounding stromal cells [60]. By using dual-colorimetric RNA in situ hybridizations, they were able to identify breast cancer cells co-expressing epithelial and mesenchymal markers. Contrary to expectations, these biphenotypic cells were observed mainly in draining lymph nodes but not at the invasive fronts of primary tumors. Alongside the heterogeneous nature of EMT process and possibility of an incomplete EMT state, it has also been suggested that molecular alterations that initiate a signal transduction cascade leading to EMT properties does not necessarily prompt acquirement of a complete mesenchymal phenotype [7].

In conclusion, our results fails to draw a direct line between the gene expression-based EMT status of a primary tumor and its associated metastatic behavior. Our findings suggest that the EMT status of the tumor, defined by the EMT-core signature, may largely be the result of the amount of stroma in the tumor (which is often larger in grade 1 tumors compared to grade 3 tumors). In this study, we have also demonstrated that immunostaining for NAT1 and TWIST1 may be of help to identify the tumor cells with EMT phenotype. We believe that our study is a valuable addition to the current literature and gives additional perspective on EMT in human metastatic breast carcinomas.

Author contributions Conceived and designed the study: CDS-H, MJV. Contributed reagents/materials/analysis tools: $\mathrm{HH}, \mathrm{GH}$. Analyzed the data: CDS-H, HH, JK, MJV. Drafted the paper: CDS-H and MJV. Read and approved the final manuscript: CDS-H, HH, JK, HMH, SLM, and MJV.

Funding This research was supported by the Center for Translational Molecular Medicine (BreastCARE).

\section{Compliance with ethical standards}

Conflict of interest Author M. J. van de Vijver holds consultant/advisory role in Le Roche and MammaPrint, Agendia (inventor patent). M. J. van de Vijver has also received research grants from Merck Sharp $\&$ Dohme. All the other authors declared that they have no conflict of interest.

Ethical approval This article does not contain any studies with human participants or animals performed by any of the authors. This study material was strictly handled after coding of the data according to national ethical guidelines of 'Code for Proper Secondary Use of Human Tissue' developed by Federation of Medical Societies (FMWV) in the Netherlands [53]. The entire study protocol was approved by the Medical Ethical Committee of the Academic Medical Center. The need for obtaining informed consent was waived by this committee.

Open Access This article is distributed under the terms of the Creative Commons Attribution 4.0 International License (http://creativeco mmons.org/licenses/by/4.0/), which permits unrestricted use, distribution, and reproduction in any medium, provided you give appropriate credit to the original author(s) and the source, provide a link to the Creative Commons license, and indicate if changes were made.

\section{References}

1. Abell AN, Jordan NV, Huang W, Prat A, Midland AA, Johnson NL, Granger DA, Mieczkowski PA, Perou CM, Gomez SM, Li L, Johnson GL (2011) MAP3K4/CBP-regulated H2B acetylation controls epithelial-mesenchymal transition in trophoblast stem cells. Cell Stem Cell 8:525-537. https://doi.org/10.1016/j. stem.2011.03.008 
2. Adam PJ, Berry J, Loader JA, Tyson KL, Craggs G, Smith P, De Belin J, Steers G, Pezzella F, Sachsenmeir KF, Stamps AC, Herath A, Sim E, O'Hare MJ, Harris AL, Terrett JA (2003) Arylamine -acetyltransferase- 1 is highly expressed in breast cancers and conveys enhanced growth and resistance to etoposide in vitro. Mol Cancer Res 1:826-835

3. Brabletz T (2012) To differentiate or not-routes towards metastasis. Nat Rev Cancer 12:425-436. https://doi.org/10.1038/nrc3265

4. Brabletz T, Jung A, Reu S, Porzner M, Hlubek F, Kunz-Schughart LA, Knuechel R, Kirchner T (2001) Variable beta-catenin expression in colorectal cancers indicates tumor progression driven by the tumor environment. Proc Natl Acad Sci USA 98:1035610361. https://doi.org/10.1073/pnas. 171610498

5. Butcher NJ, Minchin RF (2012) Arylamine N-acetyltransferase 1: a novel drug target in cancer development. Pharmacol Rev 64:147-165. https://doi.org/10.1124/pr.110.004275

6. Cheng GZ, Zhang W, Wang LH (2008) Regulation of cancer cell survival, migration, and invasion by Twist: AKT2 comes to interplay. Cancer Res 68:957-960. https://doi.org/10.1158/0008-5472. CAN-07-5067

7. Christiansen JJ, Rajasekaran AK (2006) Reassessing epithelial to mesenchymal transition as a prerequisite for carcinoma invasion and metastasis. Cancer Res 66:8319-8326. https://doi. org/10.1158/0008-5472.CAN-06-0410

8. Creighton CJ, Li X, Landis M, Dixon JM, Neumeister VM, Sjolund A, Rimm DL, Wong H, Rodriguez A, Herschkowitz JI, Fan C, Zhang X, He X, Pavlick A, Gutierrez MC, Renshaw L, Larionov AA, Faratian D, Hilsenbeck SG, Perou CM, Lewis MT, Rosen JM, Chang JC (2009) Residual breast cancers after conventional therapy display mesenchymal as well as tumor-initiating features. Proc Natl Acad Sci USA 106:13820-13825. https://doi.org/10.1073/ pnas.0905718106

9. Eckert MA, Lwin TM, Chang AT, Kim J, Danis E, Ohno-Machado L, Yang J (2011) Twist1-induced invadopodia formation promotes tumor metastasis. Cancer Cell 19:372-386. https://doi. org/10.1016/j.ccr.2011.01.036

10. Elias MC, Tozer KR, Silber JR, Mikheeva S, Deng M, Morrison RS, Manning TC, Silbergeld DL, Glackin CA, Reh TA, Rostomily RC (2005) TWIST is expressed in human gliomas and promotes invasion. Neoplasia 7:824-837

11. Endo Y, Yamashita H, Takahashi S, Sato S, Yoshimoto N, Asano T, Hato Y, Dong Y, Fujii Y, Toyama T (2014) Immunohistochemical determination of the miR-1290 target arylamine N-acetyltransferase 1 (NAT1) as a prognostic biomarker in breast cancer. BMC Cancer 14:990. https://doi.org/10.1186/1471-2407-14-990

12. Fischer KR, Durrans A, Lee S, Sheng J, Li F, Wong ST, Choi H, El Rayes T, Ryu S, Troeger J, Schwabe RF, Vahdat LT, Altorki NK, Mittal V, Gao D (2015) Epithelial-to-mesenchymal transition is not required for lung metastasis but contributes to chemoresistance. Nature 527:472-476. https://doi.org/10.1038/nature15748

13. Frisch SM, Schaller M, Cieply B (2013) Mechanisms that link the oncogenic epithelial-mesenchymal transition to suppression of anoikis. J Cell Sci 126:21-29. https://doi.org/10.1242/jcs.120907

14. Gort EH, Suijkerbuijk KP, Roothaan SM, Raman V, Vooijs M, van der Wall E, van Diest PJ (2008) Methylation of the TWIST1 promoter, TWIST1 mRNA levels, and immunohistochemical expression of TWIST1 in breast cancer. Cancer Epidemiol Biomarkers Prev 17:3325-3330. https://doi.org/10.1158/1055-9965. EPI-08-0472

15. Groger CJ, Grubinger M, Waldhor T, Vierlinger K, Mikulits W (2012) Meta-analysis of gene expression signatures defining the epithelial to mesenchymal transition during cancer progression. PLoS ONE 7:e51136. https://doi.org/10.1371/journal.pone.00511 36

16. Guo W, Keckesova Z, Donaher JL, Shibue T, Tischler V, Reinhardt F, Itzkovitz S, Noske A, Zurrer-Hardi U, Bell G, Tam WL,
Mani SA, van Oudenaarden A, Weinberg RA (2012) Slug and Sox 9 cooperatively determine the mammary stem cell state. Cell 148:1015-1028. https://doi.org/10.1016/j.cell.2012.02.008

17. Harrell JC, Prat A, Parker JS, Fan C, He X, Carey L, Anders C, Ewend M, Perou CM (2012) Genomic analysis identifies unique signatures predictive of brain, lung, and liver relapse. Breast Cancer ResTreat 132:523-535. https://doi.org/10.1007/s1054 9-011-1619-7

18. Herschkowitz JI, Simin K, Weigman VJ, Mikaelian I, Usary J, $\mathrm{Hu}$ Z, Rasmussen KE, Jones LP, Assefnia S, Chandrasekharan S, Backlund MG, Yin Y, Khramtsov AI, Bastein R, Quackenbush J, Glazer RI, Brown PH, Green JE, Kopelovich L, Furth PA, Palazzo JP, Olopade OI, Bernard PS, Churchill GA, Van Dyke T, Perou CM (2007) Identification of conserved gene expression features between murine mammary carcinoma models and human breast tumors. Genome Biol 8:R76. https://doi. org/10.1186/gb-2007-8-5-r76

19. Huang RY, Wong MK, Tan TZ, Kuay KT, Ng AH, Chung VY, Chu YS, Matsumura N, Lai HC, Lee YF, Sim WJ, Chai C, Pietschmann E, Mori S, Low JJ, Choolani M, Thiery JP (2013) An EMT spectrum defines an anoikis-resistant and spheroidogenic intermediate mesenchymal state that is sensitive to e-cadherin restoration by a src-kinase inhibitor, saracatinib (AZD0530). Cell Death Dis 4:e915. https://doi.org/10.1038/ cddis.2013.442

20. Kajiyama H, Shibata K, Terauchi M, Yamashita M, Ino K, Nawa A, Kikkawa F (2007) Chemoresistance to paclitaxel induces epithelial-mesenchymal transition and enhances metastatic potential for epithelial ovarian carcinoma cells. Int J Oncol 31:277-283

21. Kong D, Li Y, Wang Z, Sarkar FH (2011) Cancer Stem Cells and Epithelial-to-Mesenchymal Transition (EMT)-Phenotypic Cells: Are They Cousins or Twins? Cancers (Basel) 3:716-729. https:// doi.org/10.3390/cancers30100716

22. Laurieri N, Crawford MH, Kawamura A, Westwood IM, Robinson J, Fletcher AM, Davies SG, Sim E, Russell AJ (2010) Small molecule colorimetric probes for specific detection of human arylamine $\mathrm{N}$-acetyltransferase 1, a potential breast cancer biomarker. J Am Chem Soc 132:3238-3239. https://doi.org/10.1021/ja909165u

23. Lee JM, Dedhar S, Kalluri R, Thompson EW (2006) The epithelial-mesenchymal transition: new insights in signaling, development, and disease. J Cell Biol 172:973-981. https://doi. org/10.1083/jcb.200601018

24. Lee TK, Poon RT, Yuen AP, Ling MT, Kwok WK, Wang XH, Wong YC, Guan XY, Man K, Chau KL, Fan ST (2006) Twist overexpression correlates with hepatocellular carcinoma metastasis through induction of epithelial-mesenchymal transition. Clin Cancer Res 12:5369-5376. https://doi.org/10.1158/1078-0432. CCR-05-2722

25. Li X, Lewis MT, Huang J, Gutierrez C, Osborne CK, Wu MF, Hilsenbeck SG, Pavlick A, Zhang X, Chamness GC, Wong H, Rosen J, Chang JC (2008) Intrinsic resistance of tumorigenic breast cancer cells to chemotherapy. J Natl Cancer Inst 100:672679. https://doi.org/10.1093/jnci/djn123

26. Martin TA, Goyal A, Watkins G, Jiang WG (2005) Expression of the transcription factors snail, slug, and twist and their clinical significance in human breast cancer. Ann of Surg Oncol 12:488-496. https://doi.org/10.1245/ASO.2005.04.010

27. McCoy EL, Iwanaga R, Jedlicka P, Abbey NS, Chodosh LA, Heichman KA, Welm AL, Ford HL (2009) Six 1 expands the mouse mammary epithelial stem/progenitor cell pool and induces mammary tumors that undergo epithelial-mesenchymal transition. J Clin Investig 119:2663-2677. https://doi.org/10.1172/JCI37691

28. Mehrotra J, Vali M, McVeigh M, Kominsky SL, Fackler MJ, Lahti-Domenici J, Polyak K, Sacchi N, Garrett-Mayer E, Argani P, Sukumar S (2004) Very high frequency of hypermethylated 
genes in breast cancer metastasis to the bone, brain, and lung. Clin Cancer Res 10:3104-3109

29. Mironchik Y, Winnard PT Jr, Vesuna F, Kato Y, Wildes F, Pathak AP, Kominsky S, Artemov D, Bhujwalla Z, Van Diest P, Burger H, Glackin C, Raman V (2005) Twist overexpression induces in vivo angiogenesis and correlates with chromosomal instability in breast cancer. Cancer Res 65:10801-10809. https://doi. org/10.1158/0008-5472.CAN-05-0712

30. Nieto MA (2013) Epithelial plasticity: a common theme in embryonic and cancer cells. Science 342:1234850. https://doi. org $/ 10.1126 /$ science. 1234850

31. Ou DL, Chien HF, Chen CL, Lin TC, Lin LI (2008) Role of Twist in head and neck carcinoma with lymph node metastasis. Anticancer Res 28:1355-1359

32. Parker JS, Mullins M, Cheang MC, Leung S, Voduc D, Vickery T, Davies S, Fauron C, He X, Hu Z, Quackenbush JF, Stijleman IJ, Palazzo J, Marron JS, Nobel AB, Mardis E, Nielsen TO, Ellis MJ, Perou CM, Bernard PS (2009) Supervised risk predictor of breast cancer based on intrinsic subtypes. J Clin Oncol 27:1160-1167. https://doi.org/10.1200/JCO.2008.18.1370

33. Prall F (2007) Tumour budding in colorectal carcinoma. Histopathology 50:151-162. https://doi.org/10.111 1/j.1365-2559.2006.02551.x

34. Rhim AD, Mirek ET, Aiello NM, Maitra A, Bailey JM, McAllister F, Reichert M, Beatty GL, Rustgi AK, Vonderheide RH, Leach SD, Stanger BZ (2012) EMT and dissemination precede pancreatic tumor formation. Cell 148:349-361. https://doi.org/10.1016/j. cell.2011.11.025

35. Sarrio D, Rodriguez-Pinilla SM, Hardisson D, Cano A, MorenoBueno G, Palacios J (2008) Epithelial-mesenchymal transition in breast cancer relates to the basal-like phenotype. Cancer Res 68:989-997. https://doi.org/10.1158/0008-5472.CAN-07-2017

36. Satoh K, Hamada S, Kimura K, Kanno A, Hirota M, Umino J, Fujibuchi W, Masamune A, Tanaka N, Miura K, Egawa S, Motoi F, Unno M, Vonderhaar BK, Shimosegawa T (2008) Up-regulation of MSX2 enhances the malignant phenotype and is associated with twist 1 expression in human pancreatic cancer cells. Am J Pathol 172:926-939. https://doi.org/10.2353/ajpath.2008.070346

37. Savci-Heijink CD, Halfwerk H, Hooijer GK, Horlings HM, Wesseling J, van de Vijver MJ (2015) Retrospective analysis of metastatic behaviour of breast cancer subtypes. Breast Cancer Res Treat 150:547-557. https://doi.org/10.1007/s10549-015-3352-0

38. Savci-Heijink CD, Halfwerk H, Koster J, Van de Vijver MJ (2017) Association between gene expression profile of the primary tumor and chemotherapy response of metastatic breast cancer. BMC Cancer 17:755. https://doi.org/10.1186/s12885-017-3691-9

39. Savci-Heijink CD, Halfwerk H, Koster J, van de Vijver MJ (2016) A novel gene expression signature for bone metastasis in breast carcinomas. Breast Cancer Res Treat 156:249-259. https://doi. org/10.1007/s10549-016-3741-z

40. Singh A, Settleman J (2010) EMT, cancer stem cells and drug resistance: an emerging axis of evil in the war on cancer. Oncogene 29:4741-4751. https://doi.org/10.1038/onc.2010.215

41. Strizzi L, Bianco C, Normanno N, Seno M, Wechselberger C, Wallace-Jones B, Khan NI, Hirota M, Sun Y, Sanicola M, Salomon DS (2004) Epithelial mesenchymal transition is a characteristic of hyperplasias and tumors in mammary gland from MMTVCripto-1 transgenic mice. J Cell Physiol 201:266-276. https://doi. org/10.1002/jcp.20062

42. Sugamori KS, Wong S, Gaedigk A, Yu V, Abramovici H, Rozmahel R, Grant DM (2003) Generation and functional characterization of arylamine $\mathrm{N}$-acetyltransferase Nat1/Nat2 double-knockout mice. Mol Pharmacol 64:170-179. https://doi.org/10.1124/ mol.64.1.170
43. Tam WL, Weinberg RA (2013) The epigenetics of epithelialmesenchymal plasticity in cancer. Nat Med 19:1438-1449. https ://doi.org/10.1038/nm.3336

44. Tan TZ, Miow QH, Miki Y, Noda T, Mori S, Huang RY, Thiery JP (2014) Epithelial-mesenchymal transition spectrum quantification and its efficacy in deciphering survival and drug responses of cancer patients. EMBO Mol Med 6:1279-1293. https://doi. org/10.15252/emmm.201404208

45. Tarin D, Thompson EW, Newgreen DF (2005) The fallacy of epithelial mesenchymal transition in neoplasia. Cancer Res 65:59966000. https://doi.org/10.1158/0008-5472.CAN-05-0699 discussion 6000-5991.

46. Taube JH, Herschkowitz JI, Komurov K, Zhou AY, Gupta S, Yang J, Hartwell K, Onder TT, Gupta PB, Evans KW, Hollier BG, Ram PT, Lander ES, Rosen JM, Weinberg RA, Mani SA (2010) Core epithelial-to-mesenchymal transition interactome gene-expression signature is associated with claudin-low and metaplastic breast cancer subtypes. Proc Natl Acad Sci USA 107:15449-15454. https://doi.org/10.1073/pnas.1004900107

47. Terauchi M, Kajiyama H, Yamashita M, Kato M, Tsukamoto H, Umezu T, Hosono S, Yamamoto E, Shibata K, Ino K, Nawa A, Nagasaka T, Kikkawa F (2007) Possible involvement of TWIST in enhanced peritoneal metastasis of epithelial ovarian carcinoma. Clin Exp Metastasis 24:329-339. https://doi.org/10.1007/s1058 5-007-9070-1

48. Thiery JP, Acloque H, Huang RY, Nieto MA (2009) Epithelial-mesenchymal transitions in development and disease. Cell 139:871-890. https://doi.org/10.1016/j.cell.2009.11.007

49. Tiang JM, Butcher NJ, Cullinane C, Humbert PO, Minchin RF (2011) RNAi-mediated knock-down of arylamine N-acetyltransferase-1 expression induces E-cadherin up-regulation and cellcell contact growth inhibition. PLoS ONE 6:e17031. https://doi. org/10.1371/journal.pone.0017031

50. Tiang JM, Butcher NJ, Minchin RF (2015) Effects of human arylamine $\mathrm{N}$-acetyltransferase I knockdown in triple-negative breast cancer cell lines. Cancer Med 4:565-574. https://doi. org/10.1002/cam4.415

51. Tiang JM, Butcher NJ, Minchin RF (2010) Small molecule inhibition of arylamine $\mathrm{N}$-acetyltransferase Type I inhibits proliferation and invasiveness of MDA-MB-231 breast cancer cells. Biochem Biophys Res Commun 393:95-100. https://doi.org/10.1016/j. bbrc.2010.01.087

52. Tseng JC, Chen HF, Wu KJ (2015) A twist tale of cancer metastasis and tumor angiogenesis. Histol Histopathol 30:1283-1294. https://doi.org/10.14670/HH-11-638

53. Vermeulen E, Geesink I, Schmidt MK, Steegers C, Verhue D, Brom FW, Aaronson NK, van Leeuwen FE (2009) [Secondary use of human tissue: consent and better information required]. NedTijdschrGeneeskd 153:A948

54. Wicki A, Lehembre F, Wick N, Hantusch B, Kerjaschki D, Christofori G (2006) Tumor invasion in the absence of epithelial-mesenchymal transition: podoplanin-mediated remodeling of the actin cytoskeleton. Cancer Cell 9:261-272. https://doi.org/10.1016/j. ccr.2006.03.010

55. Wyckoff JB, Wang Y, Lin EY, Li JF, Goswami S, Stanley ER, Segall JE, Pollard JW, Condeelis J (2007) Direct visualization of macrophage-assisted tumor cell intravasation in mammary tumors. Cancer Res 67:2649-2656. https://doi.org/10.1158/0008-5472. CAN-06-1823

56. Yang AD, Fan F, Camp ER, van Buren G, Liu W, Somcio R, Gray MJ, Cheng H, Hoff PM, Ellis LM (2006) Chronic oxaliplatin resistance induces epithelial-to-mesenchymal transition in colorectal cancer cell lines. Clin Cancer Res 12:4147-4153. https:// doi.org/10.1158/1078-0432.CCR-06-0038

57. Yang J, Mani SA, Donaher JL, Ramaswamy S, Itzykson RA, Come C, Savagner P, Gitelman I, Richardson A, Weinberg RA 
(2004) Twist, a master regulator of morphogenesis, plays an essential role in tumor metastasis. Cell 117:927-939. https://doi. org/10.1016/j.cell.2004.06.006

58. Yang MH, Hsu DS, Wang HW, Wang HJ, Lan HY, Yang WH, Huang CH, Kao SY, Tzeng CH, Tai SK, Chang SY, Lee OK, $\mathrm{Wu}$ KJ (2010) Bmil is essential in Twist1-induced epithelialmesenchymal transition. Nat Cell Biol 12:982-992. https://doi. org/10.1038/ncb2099

59. Ye X, Tam WL, Shibue T, Kaygusuz Y, Reinhardt F, Ng Eaton E, Weinberg RA (2015) Distinct EMT programs control normal mammary stem cells and tumour-initiating cells. Nature 525:256260. https://doi.org/10.1038/nature14897

60. Yu M, Bardia A, Wittner BS, Stott SL, Smas ME, Ting DT, Isakoff SJ, Ciciliano JC, Wells MN, Shah AM, Concannon KF, Donaldson MC, Sequist LV, Brachtel E, Sgroi D, Baselga J, Ramaswamy S, Toner M, Haber DA, Maheswaran S (2013) Circulating breast tumor cells exhibit dynamic changes in epithelial and mesenchymal composition. Science 339:580-584. https://doi.org/10.1126/ science. 1228522
61. Yuen HF, Chua CW, Chan YP, Wong YC, Wang X, Chan KW (2007) Significance of TWIST and E-cadherin expression in the metastatic progression of prostatic cancer. Histopathology 50:648-658. https://doi.org/10.1111/j.1365-2559.2007.02665.x

62. Zhang Y, Toy KA, Kleer CG (2012) Metaplastic breast carcinomas are enriched in markers of tumor-initiating cells and epithelial to mesenchymal transition. Modern Pathol 25:178-184. https:// doi.org/10.1038/modpathol.2011.167

63. Zhang Z, Xie D, Li X, Wong YC, Xin D, Guan XY, Chua CW, Leung SC, Na Y, Wang X (2007) Significance of TWIST expression and its association with E-cadherin in bladder cancer. Human Pathol 38:598-606. https://doi.org/10.1016/j.humpa th.2006.10.004

64. Zheng X, Carstens JL, Kim J, Scheible M, Kaye J, Sugimoto H, Wu CC, LeBleu VS, Kalluri R (2015) Epithelial-to-mesenchymal transition is dispensable for metastasis but induces chemoresistance in pancreatic cancer. Nature 527:525-530. https://doi. org/10.1038/nature16064 